\title{
TANGERINEIRAS COMO PORTA-ENXERTOS PARA LARANJEIRA 'PÊRA'
}

\author{
Mandarins as rootstocks for 'Pêra' sweet orange trees
}

\author{
Jorgino Pompeu Junior ${ }^{1}$, Silvia Blumer ${ }^{2}$, Georgia Bertoni Pompeu ${ }^{3}$
}

\begin{abstract}
RESUMO
Laranjeiras 'Pêra' enxertadas em 11 cultivares ou híbridos de tangerineiras foram plantadas em 1988 em Itirapina (SP), num Latossolo Vermelho-Amarelo textura arenosa, no espaçamento 4,25m x 7,5m e conduzidas sem irrigação sob clima Cwa. Tristeza e declínio são endêmicos na região. As tangerineiras 'África do Sul', 'Xienkhouanga', 'Empress', 'Cleópatra', 'Wildt', 117.477 e 'Sul da África', sem diferirem entre si, induziram, em ordem decrescente, as maiores produções de frutos às laranjeiras 'Pêra', no total das quatro primeiras colheitas do experimento. Num total de nove colheitas, as cultivares Xienkhouanga, África do Sul, 117.477, Cleópatra, Empress, Wildt e Szinkon x Tizon, sem diferirem entre si, proporcionaram, em ordem decrescente, as maiores produções de frutos às laranjeiras 'Pêra'. Os porta-enxertos não determinaram diferenças significativas nas características comerciais dos frutos, porém a 'Cleópatra' induziu maturação mais precoce que os demais porta-enxertos. Apenas a 'Szwinkon' x 'Szinkon-tizon' proporcionou a formação de plantas nanicas, com altura inferior a 2,5m. Os dados médios de produção de frutos e de sólidos solúveis, concernentes a três anos consecutivos de colheita, revelaram que as laranjeiras 'Pêra' enxertadas nas tangerineiras 'Xienkhouanga' e 117.477, sem diferir das plantas enxertadas nas cultivares África do Sul, Cleópatra, Empress, Wildt e Szinkon x Tizon, foram significativamente mais produtivas em frutos e em sólidos solúveis que as enxertadas em 'Sul da África', 'Vermelha', 'Muscia' e 'Szwinkon' x 'Szinkontizon'. Nenhuma das plantas apresentou sintomas de intolerância à tristeza, ao declínio dos citros ou anel de goma na região de enxertia, considerado sintoma de incompatibilidade entre a copa e o porta-enxerto.
\end{abstract}

Termos para indexação: Citrus reshni, C. reticulata, declínio, tristeza.

\begin{abstract}
'Pera' sweet orange trees budded either on mandarins or mandarin-hybrids rootstocks were planted in 1988 at $4.25 \mathrm{~m} \times 7.5 \mathrm{~m}$ spacing on a sandy textured Oxisol in Sao Paulo state, Brazil, under Cwa climatic conditions, and managed without irrigation. Tristeza and blight diseases are endemic in the area. Trees on Africa do Sul, Xienkhouanga, Empress, Cleopatra, Wildt and 117.477 cultivars, produced the highest cumulative yields in the first four crops and in the ninth crop. Regardless of the rootstock tested no significant variation on fruit quality was observed, but 'Cleopatra' mandarin induced earlier maturation of fruit than the others roostocks. Only 'Szwinkon' x 'Szinkon-tizon' rootstocks induced dwarfed trees. 'Xienkhouanga', 117.477, 'Africa do Sul', 'Cleopatra', 'Empress', 'Wildt' and 'Szinkon' x 'Tizon' induced the highest fruit and soluble solids production by tree in the 1996-1999 period. No one trees showed symptoms of tristeza, declinio/blight or bud-union-ring symptom of incompatibility.
\end{abstract}

Index terms: Citrus reshni, C. reticulata, blight, tristeza.

\section{(Recebido em 22 de fevereiro de 2007 e aprovado em 25 de março de 2008)}

\section{INTRODUÇÃO}

A suscetibilidade dos limoeiros 'Cravo' (Citrus limonia Osbeck) e 'Volkameriano' (C. volkameriana V. Ten. \& Pasq.) ao declínio dos citros, constatado em São Paulo na década de 1970 (BERETTA et al., 1986; RODRIGUEZ et al., 1979), e à morte súbita dos citros, doença observada nos Estados de São Paulo e Minas Gerais em 1999 (BASSANEZI et al., 2003; GIMENES-FERNANDES \& BASSANEZI, 2001), vem causando a diversificação de porta-enxertos, com a utilização do citrumeleiro 'Swingle' [C. paradisi Macfad. x Poncirus trifoliata (L.) Raf.] e das tangerineiras 'Cleópatra' (C. reshni Hort. ex Tanaka) e 'Sunki' [C. sunki (Hayata) Hort. ex Tanaka], que são tolerantes a essas doenças.

Em 1987, quando este experimento foi planejado, as tangerineiras 'Cleópatra' e 'Sunki' representavam 33\% dos porta-enxertos presentes nos viveiros de mudas cítricas em São Paulo (SILVA et al., 1990). Em 2004, a presença delas estava reduzida a 23\% (POMPEU JUNIOR et al., 2004), apesar de serem os únicos porta-enxertos tolerantes ao declínio e à morte súbita dos citros compatíveis com a laranjeira 'Pêra' [C. sinensis (L.) Osbeck], a principal cultivar-copa da citricultura paulista.

\footnotetext{
'Engenheiro Agrônomo, Doutor em Agronomia, Pesquisador - Centro Avançado de Pesquisas Tecnológicas do Agronegócio dos Citros Sylvio Moreira/ CAPTA Citros Sylvio Moreira - Rodovia Anhanguera, Km 158 - Cascalho - Cx. P. 4 - 13490-970 - Cordeirópolis, SP - jorgino@centrodecitricultura.br Bolsista $1-\mathrm{C}$ do CNPq

Engenheira Agrônoma, Pós-Doutoranda em Agronomia - Departamento de Entomologia, Fitopatologia e Zoologia - Escola Superior de Agricultura Luiz de Queiroz/ESALQ - Universidade de São Paulo/USP - Cx. P. 9 - 13418-900 - Piracicaba, SP - blumer@esalq.usp.br - Bolsista da CAPES/PRODOC ${ }^{3}$ Engenheira Agrônoma, Doutoranda - Laboratório de Ecologia Aplicada - Centro de Energia Nuclear na Agricultura/CENA - Universidade de São Paulo/ USP - Avenida Centenário, 303 - São Dimas - Cx. P. 96 - 13400-970 - Piracicaba, SP - gbpompeu@cena.usp.br - Bolsista CNPq
} 
Os principais obstáculos à maior utilização dessas tangerineiras são a baixa tolerância à seca e à gomose de Phytophthora, além do início de produção mais tardio induzido pela 'Cleópatra'.

Desenvolveu-se, este trabalho, com o objetivo de avaliar o potencial de outras tangerineiras como portaenxertos para a laranjeira 'Pêra'.

\section{MATERIAL E MÉTODOS}

O experimento foi plantado em fevereiro de 1988, na Fazenda Raio de Sol, município de Itirapina, SP, num Latossolo Vermelho-Amarelo fase arenosa, no espaçamento $4,25 \mathrm{~m} \times 7,5 \mathrm{~m}$ e conduzido sem irrigação. O clima da região é do tipo Cwa (SETZER, 1966).

Foram avaliadas 11 seleções ou híbridos de tangerinas, inclusive a 'Cleópatra', já consagrada na citricultura. Na Tabela 1, listam-se os porta-enxertos estudados, indicando o nome comum, nome específico, número do acesso no Banco Ativo de Germoplasma de Citros (BAG-Citros), do Centro APTA Citros "Sylvio
Moreira" do Instituto Agronômico de Campinas, em Cordeirópolis, SP, em 1987 , e a procedência do germoplasma.

Como copa foi utilizada a laranjeira 'Pêra', clone Bianchi, selecionado pelo Sr. Alfeu Bianchi, em Bebedouro, SP, clone mais produtivo no total de 14 colheitas entre 13 clones avaliados (TEÓFILO SOBRINHO et al., 1988).

Os efeitos dos porta-enxertos foram comparados pelas produções anuais e total das quatro primeiras e das nove colheitas realizadas de 1991 a 1999, pelas principais características comerciais dos frutos determinadas de 1996 a 1999, pela produção de frutos e sólidos solúveis no período 1996-1999 e altura e diâmetro das copas em 2000. A quantidade de sólidos solúveis por caixa com $40,8 \mathrm{~kg}$ de frutos (SS/cx) foi calculada anualmente, de 1996 a 1999, utilizando a fórmula citada por Di Giorgi et al. (1990): SS/cx = \% suco x \% SS x 40,8/ 10.000 .

As plantas foram também avaliadas quanto à manifestação de sintomas de intolerância à tristeza e ao

Tabela 1 - Nomes comuns e específicos dos porta-enxertos, número do acesso no BAG-Citros do Centro APTA Citros "Sylvio Moreira" e procedência do germoplasma.

\begin{tabular}{lccc}
\hline \multicolumn{1}{c}{ Nome comum } & Nome específico ${ }^{(1)}$ & Acesso ${ }^{(2)}$ & Procedência \\
\hline 'Cleópatra' & Citrus reshni Hort. ex Tanaka & 352 & Desconhecida \\
'Vermelha' & C. reticulata Blanco & 450 & Rio Grande do Sul \\
'Szinkon' x 'Tizon' & C.suhuiensis Hort. ex Tanaka x C. \\
pappilaris Blanco & 733 & Filipinas \\
'Szwinkon' x 'Szinkon-tizon' & $?$ & 742 & Filipinas \\
'Wildt' & C. reticulata & 746 & África do Sul \\
'Sul da África' & C. reticulata & 757 & Ilhas Mauricio \\
'África do Sul' & C. reticulata & 759 & África do Sul \\
'Empress' & C. deliciosa Ten. & 761 & África do Sul \\
'Xienkhouanga' & C. reticulata & 764 & Córsega \\
117.477 & C. deliciosa & 815 & Estados Unidos
\end{tabular}

1. Segundo Germoplasm Resources Information Network (GRIN), ARS-USDA

2. Número do acesso no BAG-Citros em 1987 
declínio dos citros, endêmicos nos pomares da Fazenda Raio de Sol e pela presença de anel de goma na região de enxertia, considerado sintoma de incompatibilidade entre a copa e o porta-enxerto.

O delineamento estatístico foi em blocos ao acaso, com uma planta por parcela e dez repetições. Para a realização da análise estatística, os dados foram transformados em $\sqrt{x+1}$ e para a comparação dos tratamentos procedeu-se ao teste de Tukey, a 5\%.

\section{RESULTADOS E DISCUSSÃO}

\section{Influência dos porta-enxertos na produção de frutos}

As nove colheitas controladas foram agrupadas em dois períodos, 1991-1994 e 1995-1999, com o objetivo de avaliar o desempenho das plantas nos primeiros sete anos de vida do pomar, considerado período de formação e selecionar os porta-enxertos indutores das maiores produções nos primeiros anos de vida do pomar, característica desejável tendo em vista a ocorrência de doenças que reduzem a vida útil dos pomares, como o declínio e huanglongbing.

Na Tabela 2 são apresentadas as produções médias anuais de frutos, por planta de laranjeiras 'Pêra', de 1991 a 1999 e o total das quatro e nove colheitas mensuradas.

Os dados referentes ao total das quatro primeiras colheitas (1991-1994) revelaram que as tangerineiras 'África do Sul', 'Xienkhouanga', 'Empress', 'Cleópatra', 'Wildt', 117.477 e 'Sul da África', sem diferirem entre si, induziram, em ordem decrescente, as maiores produções de frutos às laranjeiras 'Pêra'. Entre os três porta-enxertos mais produtivos que a 'Cleópatra', destacou-se a 'África do Sul', que proporcionou as maiores produções em três colheitas, exceto em 1992, quando ocupou o terceiro lugar. Nesse período, as tangerineiras 'Xienkhouanga' e 'Empress' estiveram somente uma vez entre os três portaenxertos mais produtivos.

A 'Cleópatra' confirmou sua característica de portaenxerto indutor de início tardio de produção de frutos, vindo ocupar o terceiro lugar entre os porta-enxertos mais produtivos, apenas nas duas últimas colheitas.

No segundo período de avaliação, 1995-1999, destacou-se a 'Xienkhouanga' por ter sido o porta-enxerto mais produtivo em 1995 e o segundo nos três anos seguintes. A 'África do Sul' apresentou alternância de produção, oscilando entre o primeiro lugar em 1999 e o oitavo lugar na colheita de 1998. A ‘Empress' também não manteve posição estável entre os porta-enxertos mais produtivos, tendo ocupado o segundo lugar somente nas colheitas de 1995 e 1999. A tangerineira 117.477, que não tinha se destacado nas colheitas de 1991 a 1994, esteve entre os quatro porta-enxertos mais produtivos no período 1995-1999. A 'Cleópatra' apresentou comportamento irregular, estando entre os três porta-enxertos mais produtivos em três das cinco colheitas, tendo ocupado o primeiro lugar em duas delas.

No total das nove colheitas (1991-1999), as tangerineiras 'Xienkhouanga', 'África do Sul', 117.477, 'Cleópatra', 'Empress', 'Wildt' e 'Szinkon'x 'Tizon', sem diferirem entre si, induziram, em ordem decrescente, as maiores produções de frutos às laranjeiras 'Pêra'.

\section{Características comerciais dos frutos}

Em outubro ou novembro de 1996 a 1999 foram coletadas amostras de quinze frutos de três blocos e determinadas as características de maior interesse comercial. As médias dos valores obtidos nas quatro determinações são apresentadas na Tabela 3.

De modo geral, os porta-enxertos induziram a produção de frutos com características muito semelhantes, que não diferiram significativamente entre si quanto aos parâmetros: massa do fruto, porcentagem de sólidos solúveis e rendimento de sólidos solúveis por caixa com 40,8 kg de frutos. Somente a porcentagem de suco e a relação entre sólidos solúveis e acidez (ratio) é que apresentaram diferenças significativas, sendo que a 'Cleópatra' induziu o maior ratio $(15,4)$, conferindo maior precocidade de maturação aos frutos. $\mathrm{O}$ exame visual da cor do suco também não revelou diferenças entre os porta-enxertos.

\section{Produção de frutos e de sólidos solúveis por planta}

De modo geral, os frutos cítricos são comercializados para consumo "in natura" ou para processamento industrial atendendo à conveniência do citricultor. Assim, é desejável a seleção de porta-enxertos que induzam às copas grande produção de frutos, mas também de sólidos solúveis.

Os dados médios de produção de frutos e de sólidos solúveis concernentes ao quadriênio 1996-99, apresentados na Tabela 4, revelaram que as laranjeiras 'Pêra' enxertadas nas tangerineiras 'Xienkhouanga' e 117.477, sem diferir das enxertadas em 'África do Sul', 'Cleópatra', 'Empress', 'Wildt' e 'Szinkon' $x$ 'Tizon', foram significativamente mais produtivas em frutos e em sólidos solúveis por planta que as enxertadas em 'Sul da África', 'Vermelha', 'Muscia' e 'Szwinkon' x 'Szinkon-tizon'.

\section{Altura e diâmetro das plantas em 2000}

O diâmetro e a altura das copas das plantas estão entre os fatores que determinam o espaçamento a ser 


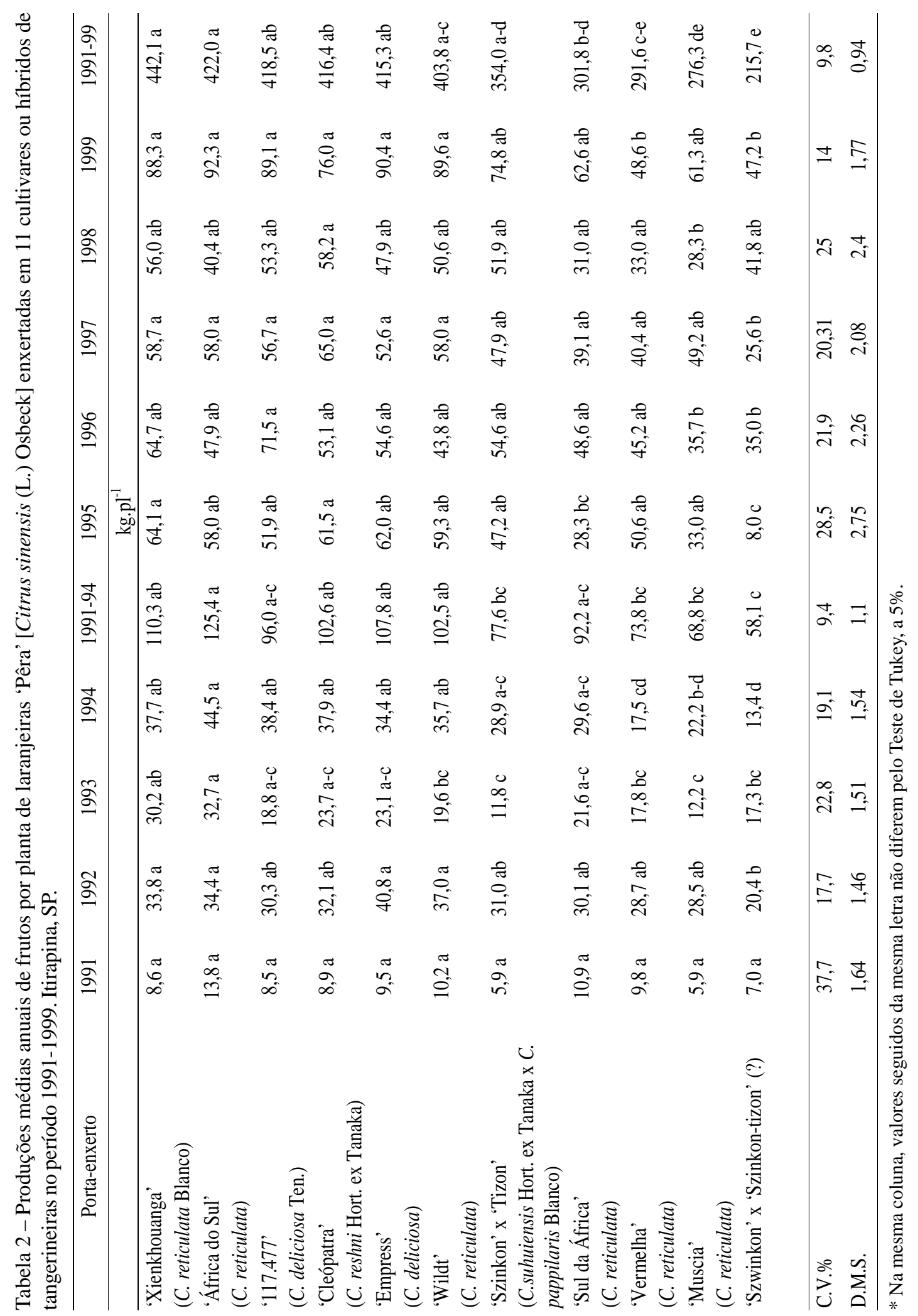


Tabela 3 - Características dos frutos de laranjeiras 'Pêra'[Citrus sinensis (L.) Osbeck] enxertadas em 11 cultivares ou híbridos de tangerineiras. Itirapina, SP. Dados médios de amostras analisadas de 1996 a 1999.

\begin{tabular}{|c|c|c|c|c|c|c|}
\hline Porta-enxertos & Altura & Diâmetro & 4 colheitas & 9 colheitas & Frutos $^{(1)}$ & $\mathrm{SST}^{(1)}$ \\
\hline & \multicolumn{2}{|c|}{------ m ------ } & \multicolumn{4}{|c|}{-------------------- kg.pl ${ }^{-1}$----------------- } \\
\hline $\begin{array}{l}\text { 'Xienkhouanga' } \\
\text { (C. reticulata } \text { Blanco) }\end{array}$ & $3,2 \mathrm{a}$ & $3,3 \mathrm{a}$ & $110,3 \mathrm{ab}$ & $442,1 \mathrm{a}$ & 269,3 a & $15,3 \mathrm{a}$ \\
\hline $\begin{array}{l}\text { 'África do Sul' } \\
\text { (C. reticulata) }\end{array}$ & $3,0 \mathrm{ab}$ & $3,4 \mathrm{a}$ & $125,4 \mathrm{a}$ & $422,0 \mathrm{a}$ & 240,7 a-d & $12,9 \mathrm{ab}$ \\
\hline $\begin{array}{l}\text { ' } 117.477 \text { ' } \\
\text { (C. deliciosa Ten.) }\end{array}$ & $2,9 \mathrm{a}-\mathrm{c}$ & $3,2 \mathrm{ab}$ & 96,0 a-c & $418,5 \mathrm{ab}$ & $269,3 \mathrm{a}$ & $15,7 \mathrm{a}$ \\
\hline $\begin{array}{l}\text { 'Cleópatra' } \\
\text { (C. reshni Hort ex Tanaka) }\end{array}$ & $3,1 \mathrm{ab}$ & $3,4 \mathrm{a}$ & $102,6 \mathrm{ab}$ & $416,4 \mathrm{ab}$ & $253,0 \mathrm{ab}$ & $14,7 \mathrm{a}$ \\
\hline $\begin{array}{l}\text { 'Empress' } \\
\text { (C. deliciosa) }\end{array}$ & $3,0 \mathrm{ab}$ & $3,3 \mathrm{a}$ & $107,8 \mathrm{ab}$ & $415,3 \mathrm{ab}$ & 244,8 a-c & $13,1 \mathrm{ab}$ \\
\hline $\begin{array}{l}\text { 'Wildt' } \\
(\text { C. reticulata })\end{array}$ & $2,8 \mathrm{bc}$ & $3,4 \mathrm{a}$ & $102,5 \mathrm{ab}$ & 403,8 a-c & 240,7 a-d & $13,5 \mathrm{ab}$ \\
\hline $\begin{array}{l}\text { 'Szinkon' } \mathrm{x} \text { 'Tizon' } \\
\text { (C.suhuiensis Hort. ex Tanaka x } \\
\text { C. pappilaris Blanco) }\end{array}$ & $2,8 \mathrm{bc}$ & 3,1 a-c & $77,6 \mathrm{bc}$ & 354,0 a-d & 228,5 a-d & $12,6 \mathrm{ab}$ \\
\hline $\begin{array}{l}\text { 'Sul da África' } \\
\text { (C. reticulata) }\end{array}$ & $2,8 \mathrm{bc}$ & $3,0 \mathrm{a}-\mathrm{c}$ & $92,2 \mathrm{a}-\mathrm{c}$ & 301,8 b-d & $175,4 \mathrm{~b}-\mathrm{e}$ & $9,7 \mathrm{bc}$ \\
\hline $\begin{array}{l}\text { 'Vermelha' } \\
\text { (C. reticulata) }\end{array}$ & $2,6 \mathrm{~cd}$ & $2,8 \mathrm{bc}$ & $73,8 \mathrm{bc}$ & $291,6 \mathrm{c}-\mathrm{e}$ & $167,3 \mathrm{de}$ & $9,3 \mathrm{bc}$ \\
\hline $\begin{array}{l}\text { 'Muscia' } \\
\text { (C. reticulata) }\end{array}$ & $2,8 \mathrm{bc}$ & $3,2 \mathrm{ab}$ & $68,8 \mathrm{bc}$ & $276,3 \mathrm{de}$ & $171,4 \mathrm{c}-\mathrm{e}$ & $9,5 \mathrm{bc}$ \\
\hline $\begin{array}{l}\text { 'Szwinkon' x 'Szinkon-tizon' } \\
(?)\end{array}$ & $2,5 \mathrm{~d}$ & $2,6 \mathrm{c}$ & $58,1 \mathrm{c}$ & $215,7 \mathrm{e}$ & $167,3 \mathrm{de}$ & $9,3 \mathrm{bc}$ \\
\hline DMS & 0,07 & 0,11 & 1,1 & 0,94 & 1,27 & 0,27 \\
\hline $\mathrm{CV}(\%)$ & 2,7 & 3,9 & 9,4 & 9,8 & 7,0 & 5,6 \\
\hline
\end{tabular}

(1) SS = Sólidos Solúveis ; ${ }^{(2)} \mathrm{cx}=$ caixa com $40,8 \mathrm{~kg}$ de frutos

*Na mesma coluna, valores seguidos da mesma letra, não diferem pelo Teste de Tukey, a 5\%.

utilizado para uma dada combinação copa/porta-enxerto. A Tabela 4 mostra a altura e o diâmetro das copas em março de 2000, quando as plantas tinham 12 anos de idade, a produção total de frutos por planta em 4 e 9 colheitas e a produção de frutos e sólidos solúveis, no período 1996 a 1999.

O exame dos dados mostrou que os porta-enxertos que induziram a formação das maiores plantas proporcionaram, também, as maiores produções de frutos no total das nove colheitas. Apenas a variedade Szwinkon x Szinkon-tizon induziu a formação de plantas nanicas, ou seja com altura inferior a $2,5 \mathrm{~m}$.

\section{Tolerância dos porta-enxertos à tristeza e ao declínio dos citros e ausência de incompatibilidade}

Nenhuma das plantas apresentou sintomas de suscetibilidade à tristeza ou ao declínio dos citros. A tolerância da 117.477 ao declínio foi descrita por Beretta et al. (1992), ao relatarem que laranjeiras 'Natal' $(C$. sinensis), enxertadas nessa tangerineira, com 11 anos de idade, não mostravam sintomas de declínio, apresentavam deslocamento normal de água e responderam negativamente ao teste de proteína $12 \mathrm{kd}$.

Nenhum dos porta-enxertos apresentou sintoma de incompatibilidade (anel de goma na região de enxertia) com a laranjeira 'Pêra'. 


\section{CONCLUSÕES}

As tangerineiras 'África do Sul', 'Xienkhouanga', 'Empress', 'Cleópatra', 'Wildt', 117.477 e 'Sul da África', sem diferirem entre si, induziram, em ordem decrescente, às maiores produções de frutos às laranjeiras 'Pêra' no total das quatro primeiras colheitas do experimento. Entre os porta-enxertos mais produtivos que a 'Cleópatra', destacou-se a 'África do Sul', que liderou em três colheitas e ocupou o terceiro lugar em 1992.

Nas cinco colheitas seguintes, o destaque foi a 'Xienkhouanga' por ter sido o porta-enxerto mais produtivo na colheita de 1995 e o segundo nas três colheitas seguintes.

No total das nove colheitas as tangerineiras 'Xienkhouanga', 'África do Sul', 117.477, 'Cleópatra', 'Empress', 'Wildt'e ‘Szinkon' x 'Tizon', sem diferirem entre si, induziram, em ordem decrescente, as maiores produções de frutos às laranjeiras 'Pêra'.

De modo geral, os porta-enxertos induziram a produção de frutos com características muito semelhantes, que não diferiram significativamente entre si. A 'Cleópatra' induziu maturação mais precoce que os demais portaenxertos.

Apenas a tangerineira 'Szwinkon' x 'Szinkon-tizon' proporcionou a formação de plantas com altura inferior a $2,5 \mathrm{~m}$.

Os dados médios de produção de frutos e de sólidos solúveis concernentes a três anos consecutivos revelaram que as laranjeiras 'Pêra' enxertadas nas tangerineiras 'Xienkhouanga' e 117.477, sem diferir das plantas enxertadas nas cultivares África do Sul, Cleópatra, Empress, Wildt e Szinkon x Tizon, foram significativamente mais produtivas em frutos e em sólidos solúveis que as enxertadas em 'Sul da África', 'Vermelha', 'Muscia' e 'Szwinkon' x 'Szinkon-tizon'.

Nenhuma das plantas apresentou sintomas de intolerância à tristeza, ao declínio dos citros ou de incompatibilidade (anel de goma na região de enxertia) entre a laranjeira 'Pêra' e o porta-enxerto.

\section{AGRADECIMENTOS}

Às Fazendas Reunidas Raio de Sol, à Fapesp (Proc.01/08455-0), ao CNPq (Proc. 300707/80-0) e ao Fundo de Defesa da Citricultura (Fundecitrus).

\section{REFERÊNCIAS BIBLIOGRÁFICAS}

BASSANEZI, R. B.; BERGAMIN FILHO, A.; AMORIM, L.; GIMENES-FERNANDES, N.; GOTTWALD, T. R.; BOVÉ, J. M. Spatial and temporal analyses of citrus sudden death, as a tool to generated hypotheses concerning its etiology. Phytopathology, Saint Paul, v. 93, n. 4, p. 502512,2003

BERETTA, M. J. G.; POMPEU JUNIOR, J.; TEÓFILO SOBRINHO, J.; ROSSETTI, V. V.; FOGAÇA, M.; LEFRÉVE, A. F. V.; JACON, J. R. Avaliação do declínio de plantas cítricas em clones de limões Cravo e Volkameriano. In: CONGRESSO BRASILEIRO DE FRUTICULTURA, 8., 1986, Brasília, DF. Anais... Brasília, DF: Embrapa-DDT/CNPq, 1986. p. 243-247.

DI GIORGI, F.; IDE, Y. B.; DIB, K.; MARCHI, R. J.; TRIBONI, H. R.; WAGNER, R. L. Contribuição ao estudo do comportamento de algumas variedades de citros e suas implicações agroindustriais. Laranja, Cordeirópolis, v. 11, n. 2, p. 567-612, 1990.

GIMENES-FERNANDES, N.; BASSANEZI, R. B. Doença de causa desconhecida afeta pomares cítricos no norte de São Paulo e sul do Triângulo Mineiro. Summa Phytopathologica, Jaguariúna, v. 27, p. 93, 2001.

POMPEU JUNIOR, J.; SALVA, R.; BLUMER, S. Copas e portaenxertos nos viveiros de mudas cítricas do Estado de São Paulo. Laranja, Cordeirópolis, v. 25, n. 2, p. 413-422, 2004.

RODRIGUEZ, O.; ROSSETTI, V. V.; MULLER, G. W.; MOREIRA, C. S.; PRATES, H. S.; NEGRI, J. D.; GREVE, A. Declínio de plantas cítricas em São Paulo. In: CONGRESSO BRASILEIRO DE FRUTICULTURA, 5., 1979, Pelotas. Anais... Pelotas: Sociedade Brasileira de Fruticultura, 1979.p. 927-932.

SETZER, J. Atlas climático e ecológico do Estado de São Paulo. São Paulo: Comissão Interestadual da Bacia ParanáUruguai, $1966.61 \mathrm{p}$.

SILVA, M. L. M.; SCRICH JUNIOR, C.; POMPEU JUNIOR, J.; BERETTA, M. J. A. G.; NEGRI, J. D. de; ROSSETTI, V. V. Evolution of the use of rootstocks varieties in citrus nurseries of São Paulo State, Brasil, due to declinio. In: CONGRESS OF THE INTERNATIONAL SOCIETY OF CITRUS NURSERYMEN, 3., 1990, Sidney. Proceedings... Sidney: International Society of Citrus Nurserymen, 1990. p. 22-27.

TEOFILO SOBRINHO, J.; POMPEU JUNIOR, J.; FIGUEIREDO, J. O.; GUIRADO, N.; BARBIN, D. Competição de treze clones de laranja Pêra enxertados sobre limão Cravo: resultados de 14 anos de produção. In: CONGRESSO BRASILEIRO DE FRUTICULTURA, 9., 1987, Campinas. Anais... Campinas: Sociedade Brasileira de Fruticultura, 1988. p. 250-255. 